\title{
Study on Factors Effecting Weld Pool Geometry of Pulsed Current Micro Plasma Arc Welded AISI 304L Austenitic Stainless Steel Sheets Using Statistical Approach
}

\author{
Kondapalli Siva Prasad ${ }^{1 *}$, Chalamalasetti Srinivasa Rao ${ }^{2}$, Damera Nageswara Rao ${ }^{3}$ \\ ${ }^{1}$ Department of Mechanical Engineering, Anil Neerukonda Institute of Technology \& Sciences, Visakhapatnam, India \\ ${ }^{2}$ Department of Mechanical Engineering, Andhra University, Visakhapatnam, India \\ ${ }^{3}$ Centurion University of Technology \& Management, Odisha, India \\ Email: "kspanits@gmail.com
}

Received March 27, 2012; revised May 5, 2012; accepted June 2, 2012

\begin{abstract}
Pulsed current Micro Plasma Arc Welding is used to joint thin sheets of AISI 304L sheets, which are used in manufacturing of metallic bellows and diaphragms. In this article the effects of pulsing current parameters on weld pool geometry namely front width, back width, front height and back height of pulsed current micro plasma arc welded AISI 304L stainless steel sheets was analyzed. Four factors, five levels, central composite design was used to develop mathematical models, incorporating pulsed current parameters and weld pool geometry. The mathematical models have been developed by Response Surface Method. The adequacy of the models was checked by ANOVA technique. Variation of output responses with input process variables are discussed. By using the developed mathematical models, weld pool geometry parameters can be predicted.
\end{abstract}

Keywords: Pulsed Current; Micro Plasma Arc Welding; Mathematical Model; AISI 304l Stainless Steel; Weld Pool Geometry; ANOVA

\section{Introduction}

Austenitic Chromium-Nickel stainless steels had gathered wide acceptance in the fabrication of components which require high temperature resistance and corrosion resistance [1], such as metallic bellows used for fabrication of expansion joints, which are used in aircraft, aerospace and petroleum industry, in which they are subjected to high temperature and corrosive environment. The present paper focuses on bellow manufacturing in which a thin sheet is to fold round in shape and the edges has to be welded longitudinally.

The plasma welding process was introduced to the welding industry in 1964 as a method of bringing better control to the arc welding process in lower current ranges [2]. Today, plasma retains the original advantages it brought to the industry by providing an advanced level of control and accuracy to produce high quality welds in both miniature and pre precision applications and to provide long electrode life for high production requirements at all levels of amperage. Plasma welding is equally suited to manual and automatic applications. It is used in a variety of joining operations ranging from welding of

*Corresponding author. miniature components to seam welding to high volume production welding and many others.

Pulsed current MPAW involves cycling the welding current at selected regular frequency. The maximum current is selected to give adequate penetration and bead contour, while the minimum is set at a level sufficient to maintain a stable arc $[3,4]$. This permits arc energy to be used effectively to fuse a spot of controlled dimensions in a short time producing the weld as a series of overlapping nuggets. By contrast, in constant welding current, the heat required to melt the base material is supplied only during the peak current pulses allowing the heat to dissipate into the base material leading to narrower Heat Affected Zone (HAZ). Advantages include improved bead contours, greater tolerance to heat sink variations, lower heat input requirements reduced residual stresses and distortion, refinement of fusion zone microstructure and reduced width of HAZ.

From the literature review [5-12] it was understood that many researchers studied the influence of plasma arc welding process parameters on bead geometry using statistical techniques like Taguchi, Response Surface Technique, Artificial Neural Network, Genetic Algorithm. However in all the works reported so far researchers have concentrated on materials of higher thickness; but not 
much effort was made to develop mathematical models to predict the same especially when welding thin stainless steel sheets in a flat position. An attempt is made to correlate important pulsed current MPAW process parameters to weld pool geometry of SS 304L stainless steel sheets by developing mathematical models using statistical tools.

\section{Experimental Setup}

\subsection{Materials and Methodology}

AISI 304L stainless steel sheets of $100 \times 150 \times 0.25 \mathrm{~mm}$ are welded autogenously with square butt joint without edge preparation. The chemical composition of AISI $304 \mathrm{~L}$ stainless steel sheet procured from Salem Steel Plant, India is given in Table 1. High purity argon gas (99.99\%) is used as a shielding gas and a trailing gas right after welding to prevent absorption of oxygen and nitrogen from the atmosphere. The welding has been carried out under the welding conditions presented in Table 2. From the literature four important factors of pulsed current
MPAW as presented in Table $\mathbf{3}$ are chosen. A large number of trail experiments are carried out using 0.25 mm thick AISI $304 \mathrm{~L}$ stainless steel sheets to find out the feasible working limits of pulsed current MPAW process parameters. Due to wide range of factors, it was decided to use four factors, five levels, rotatable central composite design matrix to perform the number of experiments for investigation. Table 4 indicates the 31 set of coded conditions used to form the design matrix. The first sixteen experimental conditions (rows) have been formed for main effects. The next eight experimental conditions are called as corner points and the last seven experimental conditions are known as center points. The method of designing such matrix is dealt elsewhere [13,14]. For the convenience of recording and processing the experimental data, the upper and lower levels of the factors are coded as +2 and -2 , respectively and the coded values of any intermediate levels can be calculated by using the expression [15].

$$
X_{i}=2\left[2 X-\left(X_{\max }+X_{\min }\right)\right] /\left(X_{\max }-X_{\min }\right)
$$

Table 1. Chemical composition of AISI 304L stainless steel sheets (wt\%).

\begin{tabular}{cccccccccc}
\hline $\mathrm{C}$ & $\mathrm{Si}$ & $\mathrm{Mn}$ & $\mathrm{P}$ & $\mathrm{S}$ & $\mathrm{Cr}$ & $\mathrm{Ni}$ & $\mathrm{Mo}$ & $\mathrm{Ti}$ & $\mathrm{N}$ \\
\hline 0.021 & 0.35 & 1.27 & 0.030 & 0.001 & 18.10 & 8.02 & -- & -- & 0.053 \\
\hline
\end{tabular}

Table 2. Welding conditions.

\begin{tabular}{ll}
\hline Power source & Secheron micro plasma arc machine \\
\hline Model number & PLASMAFIX 50E \\
Polarity & DCEN \\
Mode of operation & Pulse mode \\
Electrode & $2 \%$ thoriated tungsten electrode \\
Electrode diameter & $1 \mathrm{~mm}$ \\
Plasma gas & $95 \%$ argon \& 5\% hydrogen \\
Plasma gas flow rate & $6 \mathrm{Lpm}$ \\
Shielding gas & Argon \\
Shielding gas flow rate & $0.4 \mathrm{Lpm}$ \\
Purging gas & Argon \\
Purging gas flow rate & $0.4 \mathrm{Lpm}$ \\
Copper nozzle diameter & $1 \mathrm{~mm}$ \\
Nozzle to plate distance & $1 \mathrm{~mm}$ \\
Welding speed & $260 \mathrm{~mm} / \mathrm{min}$ \\
Torch position & Vertical \\
Operation type & Automatic \\
\hline
\end{tabular}

Table 3. Important factors and their levels.

\begin{tabular}{cccccccc}
\hline \multicolumn{7}{c}{ Levels } \\
\hline SI No. & Input factor & Units & -2 & -1 & 0 & +1 & +2 \\
1 & Peak current & Amps & 6 & 6.5 & 7 & 7.5 & 8 \\
2 & Back current & Amps & 3 & 3.5 & 4 & 4.5 & 5 \\
3 & Pulse & No's/sec & 20 & 30 & 40 & 50 & 60 \\
4 & Pulse width & $\%$ & 30 & 40 & 50 & 60 & 70 \\
\hline
\end{tabular}


Table 4. Design matrix and experimental results.

\begin{tabular}{|c|c|c|c|c|c|c|c|c|}
\hline SI No. & $\begin{array}{l}\text { Peak current } \\
\text { (Amps) }\end{array}$ & $\begin{array}{l}\text { Back current } \\
\text { (Amps) }\end{array}$ & $\begin{array}{c}\text { Pulse } \\
\text { (No/sec) }\end{array}$ & $\begin{array}{l}\text { Pulse width } \\
\text { (\%) }\end{array}$ & $\begin{array}{l}\text { Front width } \\
\quad(\mathrm{mm})\end{array}$ & $\begin{array}{c}\text { Back width } \\
\text { (mm) }\end{array}$ & $\begin{array}{l}\text { Front height } \\
\quad(\mathrm{mm})\end{array}$ & $\begin{array}{l}\text { Back height } \\
\text { (mm) }\end{array}$ \\
\hline 1 & -1 & -1 & -1 & -1 & 1.448 & 1.374 & 0.0609 & 0.0498 \\
\hline 2 & 1 & -1 & -1 & -1 & 1.592 & 1.522 & 0.0588 & 0.0458 \\
\hline 3 & -1 & 1 & -1 & -1 & 1.383 & 1.324 & 0.0630 & 0.0490 \\
\hline 4 & 1 & 1 & -1 & -1 & 1.504 & 1.442 & 0.0569 & 0.0439 \\
\hline 5 & -1 & -1 & 1 & -1 & 1.454 & 1.401 & 0.0581 & 0.0453 \\
\hline 6 & 1 & -1 & 1 & -1 & 1.487 & 1.418 & 0.0595 & 0.0466 \\
\hline 7 & -1 & 1 & 1 & -1 & 1.469 & 1.378 & 0.0599 & 0.0468 \\
\hline 8 & 1 & 1 & 1 & -1 & 1.462 & 1.402 & 0.0578 & 0.0448 \\
\hline 9 & -1 & -1 & -1 & 1 & 1.529 & 1.451 & 0.0599 & 0.0470 \\
\hline 10 & 1 & -1 & -1 & 1 & 1.591 & 1.508 & 0.0571 & 0.0441 \\
\hline 11 & -1 & 1 & -1 & 1 & 1.520 & 1.447 & 0.0572 & 0.0441 \\
\hline 12 & 1 & 1 & -1 & 1 & 1.562 & 1.506 & 0.0552 & 0.0423 \\
\hline 13 & -1 & -1 & 1 & 1 & 1.442 & 1.372 & 0.0605 & 0.0474 \\
\hline 14 & 1 & -1 & 1 & 1 & 1.384 & 1.306 & 0.0590 & 0.0456 \\
\hline 15 & -1 & 1 & 1 & 1 & 1.506 & 1.430 & 0.0600 & 0.0470 \\
\hline 16 & 1 & 1 & 1 & 1 & 1.420 & 1.356 & 0.0584 & 0.0464 \\
\hline 17 & -2 & 0 & 0 & 0 & 1.521 & 1.451 & 0.0598 & 0.0468 \\
\hline 18 & 2 & 0 & 0 & 0 & 1.580 & 1.514 & 0.0569 & 0.0439 \\
\hline 19 & 0 & -2 & 0 & 0 & 1.452 & 1.380 & 0.0575 & 0.0445 \\
\hline 20 & 0 & 2 & 0 & 0 & 1.427 & 1.358 & 0.0564 & 0.0434 \\
\hline 21 & 0 & 0 & -2 & 0 & 1.596 & 1.527 & 0.0582 & 0.0453 \\
\hline 22 & 0 & 0 & 2 & 0 & 1.466 & 1.397 & 0.0564 & 0.0434 \\
\hline 23 & 0 & 0 & 0 & -2 & 1.400 & 1.337 & 0.0636 & 0.0516 \\
\hline 24 & 0 & 0 & 0 & 2 & 1.461 & 1.384 & 0.0602 & 0.0472 \\
\hline 25 & 0 & 0 & 0 & 0 & 1.531 & 1.462 & 0.0606 & 0.0476 \\
\hline 26 & 0 & 0 & 0 & 0 & 1.581 & 1.512 & 0.0597 & 0.0467 \\
\hline 27 & 0 & 0 & 0 & 0 & 1.523 & 1.452 & 0.0607 & 0.0477 \\
\hline 28 & 0 & 0 & 0 & 0 & 1.519 & 1.450 & 0.0606 & 0.0476 \\
\hline 29 & 0 & 0 & 0 & 0 & 1.504 & 1.432 & 0.0607 & 0.0477 \\
\hline 30 & 0 & 0 & 0 & 0 & 1.501 & 1.433 & 0.0576 & 0.0446 \\
\hline 31 & 0 & 0 & 0 & 0 & 1.401 & 1.332 & 0.0597 & 0.0456 \\
\hline
\end{tabular}

where $X_{i}$ is the required coded value of a parameter $X$. The $X$ is any value of the parameter from $X_{\min }$ to $X_{\max }$, where $X_{\min }$ is the lower limit of the parameter and $X_{\max }$ is the upper limit of the parameter.

\subsection{Measurement of Weld Pool Geometry}

Three metallurgical samples were cut from each joint, with the first sample being located at $25 \mathrm{~mm}$ behind the trailing edge of the crater at the end of the weld and mounted using Bakelite. Sample preparation and mounting was done as per ASTM E 3-1 standard. The transverse face of the samples were surface grounded using 120 grit size belt with the help of belt grinder, polished using grade 1/0 (245 mesh size), grade 2/0 (425 mesh size) and grade 3/0 (515 mesh size) sand paper. The specimens were further polished by using aluminum oxide initially and the by utilizing diamond paste and velvet cloth in a polishing machine. The polished specimens were macroetched by using $10 \%$ Oxalic acid solution to reveal the geometry of the weld pool (Figure 1) [16]. Several criti- 
cal parameters, such as front width, back width, front height and back height of the weld pool geometry (Figure 2) [16] are measured. The weld pool geometry was measured using Metallurgical Microscope (Make: Dewinter Technologie, Model No. DMI-CROWN-II) at 100× magnification.

\section{Developing Mathematical Models}

In most RSM problems [17-19], the form of the relationship between the response (Y) and the independent variables is unknown. Thus the first step in RSM is to find a suitable approximation for the true functional relationship between the response and the set of independent variables.

Usually, a low order polynomial is some region of the independent variables is employed. If the response is well modeled by a linear function of the independent variables then the approximating function in the first order model.

$$
Y=b_{o}+\sum b_{i} x_{i}+\epsilon
$$

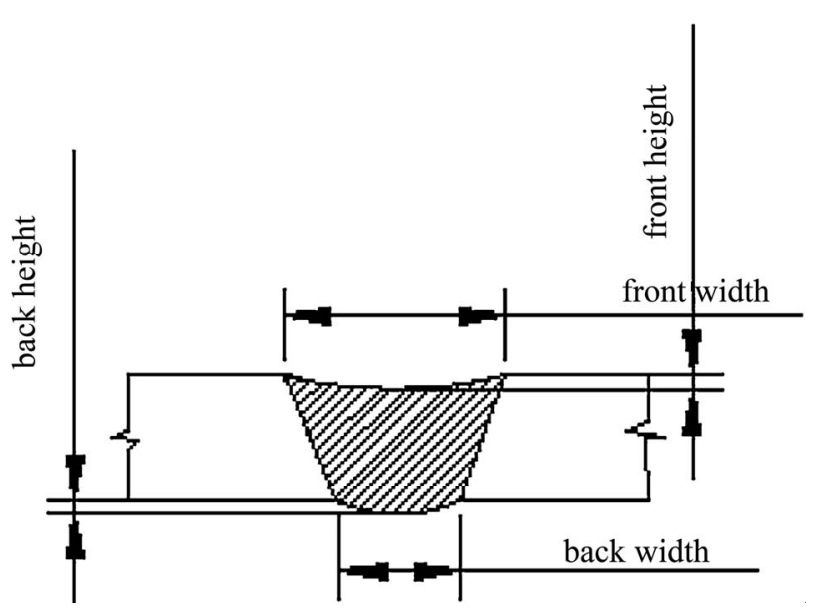

Figure 1. Typical weld pool geometry [20].

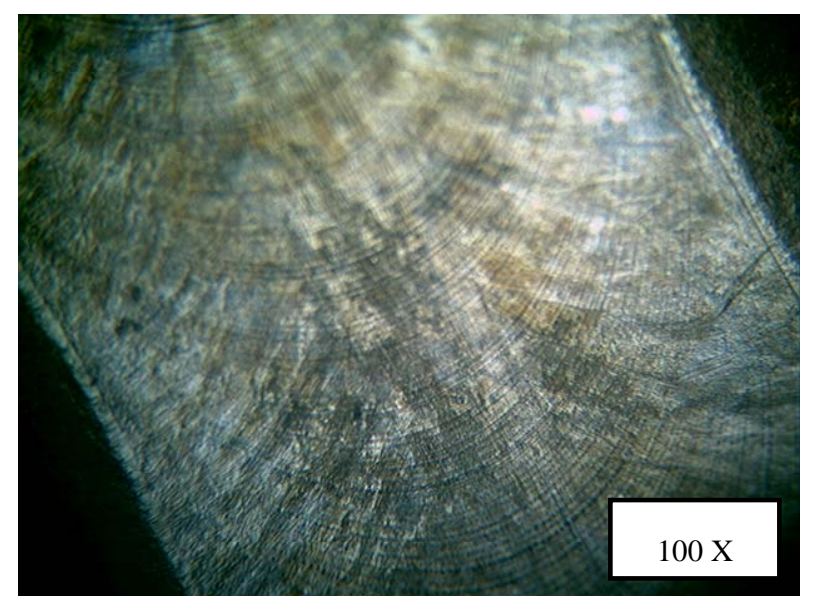

Figure 2. Macrographs of weld pool.
If interaction terms are added to main effects or first order model, then we have a model capable of representing some curvature in the response function.

$$
Y=b_{o}+\sum b_{i} x_{i}+\sum \sum b_{i j} x_{j} x_{j}+\epsilon
$$

The curvature, of course, results from the twisting of the plane induced by the interaction term $\beta_{i j} x_{i} x_{j}$.

There are going to be situations where the curvature in the response function is not adequately modeled by Equation (3). In such cases, a logical model to consider is

$$
Y=b_{o}+\sum b_{i} x_{i}+\sum b_{i i} x_{i}^{2}+\sum \sum b_{i j} x_{i} x_{j}+\epsilon
$$

where $b_{i i}$ represents pure second order or quadratic effects. Equation (4) is a second order response surface model.

Using MINITAB 14 statistical software package, the significant coefficients were determined and final models were developed using only theses coefficients to estimate front width, back width, front height and back height of the weld pool geometry.

Front Width (FW)

$$
\begin{aligned}
\mathrm{FW}= & 1.50857+0.01538 X_{1}-0.00629 X_{2} \\
& -0.03187 X_{3}+0.01154 X_{4}-0.02007 X_{4}^{2} \\
& -0.03044 X_{1} X_{3}-0.02469 X_{3} X_{4}
\end{aligned}
$$

Back Width (BW)

$$
\begin{aligned}
\mathrm{BW}= & 1.143900+0.01704 X_{1}-0.00462 X_{2} \\
& -0.03212 X_{3}+0.00871 X_{4} \\
& -0.02024 X_{4}^{2}-0.03006 X_{1} X_{3}
\end{aligned}
$$

Front Height (FH)

$$
\begin{aligned}
\mathrm{FH}= & 0.059943-0.000942 X_{1}-0.000317 X_{2} \\
& +0.000025 X_{3}-0.000600 X_{4}-0.000704 X_{2}^{2}(7) \\
& -0.000617 X_{3}^{2}+0.000800 X_{3} X_{4}
\end{aligned}
$$

Back Height (BH)

$$
\begin{aligned}
\mathrm{BH}= & 0.046786-0.00946 X_{1}-0.000396 X_{2} \\
& -0.000004 X_{3}-0.000704 X_{4}-0.000670 X_{2}^{2}(8) \\
& +0.000692 X_{4}^{2}
\end{aligned}
$$

where $X_{1}, X_{2}, X_{3}$ and $X_{4}$ are the coded values of front width, back width, front height and back height respectively.

\section{Checking the Adequacy of the Developed Models}

The adequacy of the developed models was tested using the analysis of variance technique (ANOVA). As per this technique, if the calculated value of the $F_{\text {ratio }}$ of the developed model is less than the standard $F_{\text {ratio }}$ (from $F$ table) value at a desired level of confidence (say 99\%), then the model is said to be adequate within the confi 
dence limit. ANOVA test results are presented in Table 5 for all the models. From the table it is understood that the developed mathematical models are found to be adequate at $99 \%$ confidence level. Coefficient of determina-

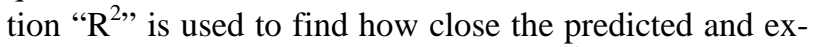

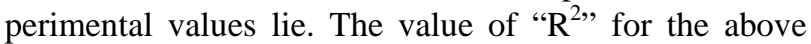
developed models is found to be about 0.84 , which indicates good correlation exists between the experimental values and predicted values.

Figures 3-6 indicate the scatter plots for weld pool geometry parameters of the weld joint and reveals that the actual and predicted values are close to each other with in the specified limits.

Confirmation tests are carried out at different conditions to check the accuracy of the developed models. The details of confirmation tests are presented in Table 6.

From Table 6 it is very clear that the developed model holds good for set of input parameters other than that specified in design matrix. However it is important that the developed model is valid within the range of specified weld input parameters. The experimental and predicted values of weld pool geometry parameters and error \% is presented in Table 7 .

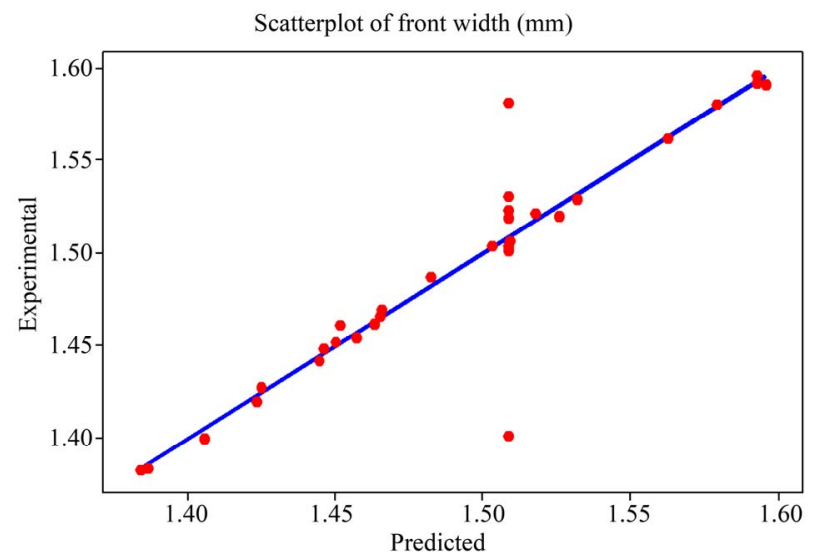

Figure 3. Scatter plot of front width.

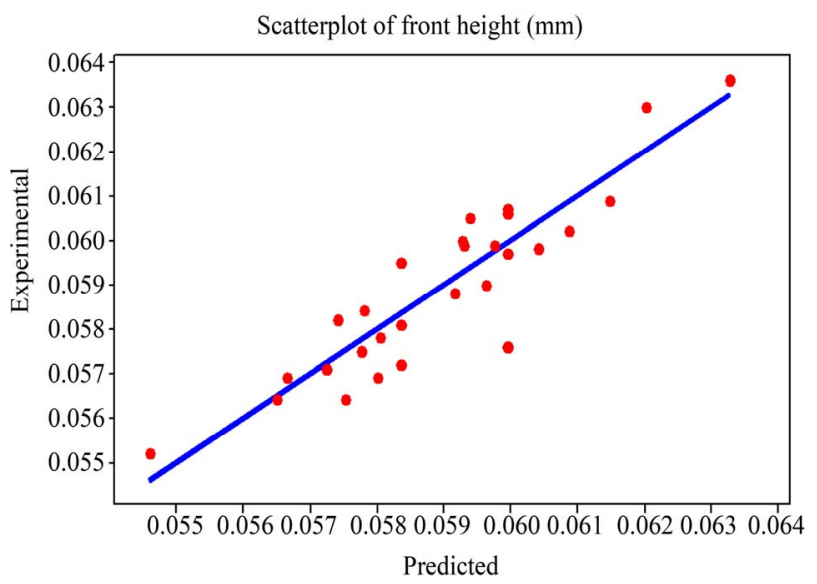

Figure 5. Scatter plot of front height.

\section{Results \& Discussion}

The mathematical models developed above can be employed to predict the geometry of weld pool geometry dimensions and their relationships for the range of parameters used in the investigation by substituting their respective values in coded form. Based on these models, the effects of the process parameters on the weld pool geometry dimensions are computed and plotted as depicted in Figures 7-10.

\subsection{Effect of Peak Current on Weld Pool Geometry Parameters}

Front width and back width decreases with peak current up to 6.5 Amperes and thereafter increases, where as front height and back height increases up to 6.5 Amperes and thereafter decreases. At lower peak currents up to 6.5 Amperes, the heat input is less and hence low melting rate of the parent metal leading to lower front width and back width. When peak current increases beyond 6.5 Amperes the heat input also increases and hence high melting rate of parent metal leading to higher front width and back width.

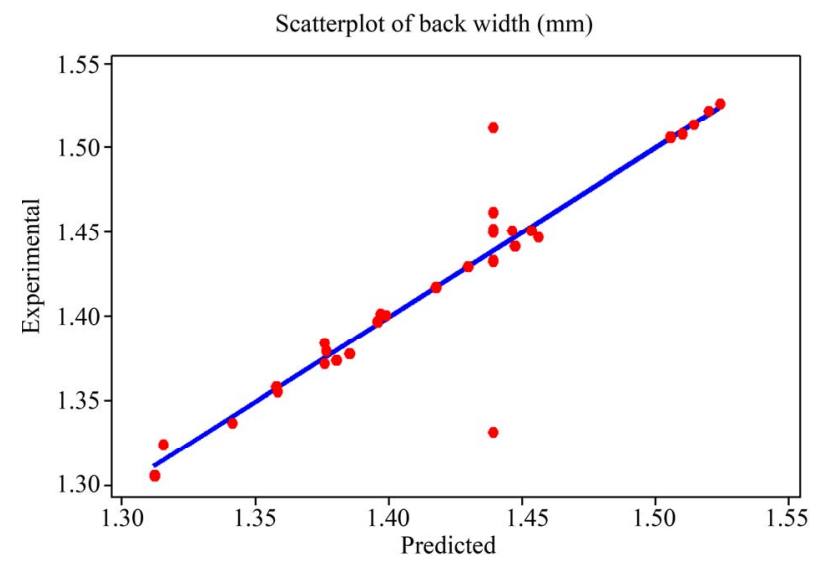

Figure 4. Scatter plot of back width.

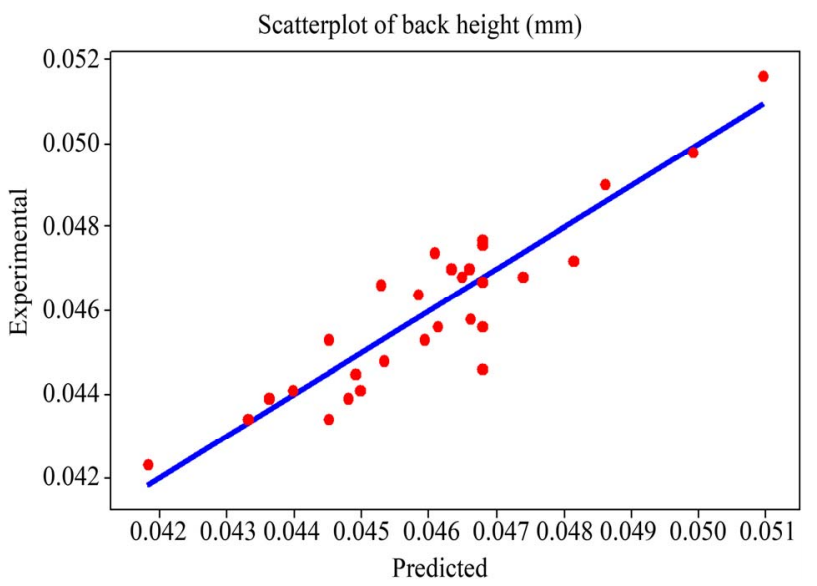

Figure 6. Scatter plot of back height. 
Table 5. ANOVA table.

\begin{tabular}{|c|c|c|c|c|c|c|}
\hline Front Width & & & & & & \\
\hline Source & $\mathrm{DF}$ & Seq SS & Adj SS & Adj MS & $\mathrm{F}$ & $\mathrm{P}$ \\
\hline Regression & 14 & 0.100167 & 0.100167 & 0.007155 & 6.36 & 0.000 \\
\hline Linear & 4 & 0.034205 & 0.034205 & 0.008551 & 7.60 & 0.001 \\
\hline Square & 4 & 0.025671 & 0.025671 & 0.006418 & 5.70 & 0.005 \\
\hline Interaction & 6 & 0.040291 & 0.040291 & 0.006715 & 5.96 & 0.002 \\
\hline Residual Error & 16 & 0.018013 & 0.018013 & 0.001126 & & \\
\hline Lack-of-Fit & 10 & 0.000298 & 0.000298 & 0.000030 & 0.01 & 1.000 \\
\hline Pure Error & 6 & 0.017716 & 0.017716 & 0.002953 & & \\
\hline Total & 30 & 0.118180 & & & & \\
\hline \multicolumn{7}{|l|}{ Back Width } \\
\hline Source & DF & Seq SS & Adj SS & Adj MS & $\mathrm{F}$ & $\mathrm{P}$ \\
\hline Regression & 14 & 0.098374 & 0.098374 & 0.007027 & 6.18 & 0.000 \\
\hline Linear & 4 & 0.034072 & 0.034072 & 0.008518 & 7.49 & 0.001 \\
\hline Square & 4 & 0.026461 & 0.026461 & 0.006615 & 5.82 & 0.004 \\
\hline Interaction & 6 & 0.037841 & 0.037841 & 0.006307 & 5.55 & 0.003 \\
\hline Residual Error & 16 & 0.018191 & 0.018191 & 0.001137 & & \\
\hline Lack-of-Fit & 10 & 0.000509 & 0.000509 & 0.000051 & 0.02 & 1.000 \\
\hline Pure Error & 6 & 0.017682 & 0.017682 & 0.002947 & & \\
\hline Total & 30 & 0.116565 & & & & \\
\hline \multicolumn{7}{|l|}{ Front Height } \\
\hline Source & $\mathrm{DF}$ & Seq SS & Adj SS & Adj MS & $\mathrm{F}$ & $\mathrm{P}$ \\
\hline Regression & 14 & 0.000092 & 0.000092 & 0.000007 & 5.43 & 0.001 \\
\hline Linear & 4 & 0.000032 & 0.000032 & 0.000008 & 6.71 & 0.002 \\
\hline Square & 4 & 0.000038 & 0.000038 & 0.000009 & 7.85 & 0.001 \\
\hline Interaction & 6 & 0.000021 & 0.000021 & 0.000004 & 2.97 & 0.038 \\
\hline Residual Error & 16 & 0.000019 & 0.000019 & 0.000001 & & \\
\hline Lack-of-Fit & 10 & 0.000012 & 0.000012 & 0.000001 & 0.92 & 0.570 \\
\hline Pure Error & 6 & 0.000008 & 0.000008 & 0.000001 & & \\
\hline Total & 30 & 0.000111 & & & & \\
\hline \multicolumn{7}{|l|}{ Back Height } \\
\hline Source & $\mathrm{DF}$ & Seq SS & Adj SS & Adj MS & $\mathrm{F}$ & $\mathrm{P}$ \\
\hline Regression & 14 & 0.000102 & 0.000102 & 0.000007 & 5.54 & 0.001 \\
\hline Linear & 4 & 0.000037 & 0.000037 & 0.000009 & 7.05 & 0.002 \\
\hline Square & 4 & 0.000041 & 0.000041 & 0.000010 & 7.87 & 0.001 \\
\hline Interaction & 6 & 0.000024 & 0.000024 & 0.000004 & 2.99 & 0.037 \\
\hline Residual Error & 16 & 0.000021 & 0.000021 & 0.000001 & & \\
\hline Lack-of-Fit & 10 & 0.000012 & 0.000012 & 0.000001 & 0.78 & 0.656 \\
\hline Pure Error & 6 & 0.000009 & 0.000009 & 0.000002 & & \\
\hline Total & 30 & 0.000123 & & & & \\
\hline
\end{tabular}

Where SS = sum of squares; MS = mean squares; DF = degree of freedom; F = fisher's ratio. 
Table 6. Confirmation test results.

\begin{tabular}{|c|c|c|c|c|c|c|c|c|c|c|c|}
\hline \multirow{3}{*}{$\begin{array}{c}\text { Peak } \\
\text { current } \\
\text { (Amperes) }\end{array}$} & \multirow{3}{*}{$\begin{array}{c}\text { Back } \\
\text { current } \\
\text { (Amperes) }\end{array}$} & \multirow{3}{*}{$\begin{array}{l}\text { Pulse rate } \\
\text { (pulses/ } \\
\text { second) }\end{array}$} & \multirow{3}{*}{$\begin{array}{l}\text { Pulse } \\
\text { width } \\
(\%)\end{array}$} & \multicolumn{8}{|c|}{ Weld pool geometry parameters (mm) } \\
\hline & & & & \multicolumn{4}{|c|}{ Experimental } & \multicolumn{4}{|c|}{ Predicted } \\
\hline & & & & $\begin{array}{l}\text { Front } \\
\text { Width }\end{array}$ & $\begin{array}{c}\text { Back } \\
\text { Width }\end{array}$ & $\begin{array}{l}\text { Front } \\
\text { Height }\end{array}$ & $\begin{array}{c}\text { Back } \\
\text { Height }\end{array}$ & $\begin{array}{l}\text { Front } \\
\text { Width }\end{array}$ & $\begin{array}{c}\text { Back } \\
\text { Width }\end{array}$ & $\begin{array}{c}\text { Front } \\
\text { Height }\end{array}$ & $\begin{array}{c}\text { Back } \\
\text { Height }\end{array}$ \\
\hline 2 & 2 & 2 & 2 & 1.192 & 1.246 & 0.056 & 0.034 & 1.185 & 1.234 & 0.054 & 0.029 \\
\hline 0 & 2 & 2 & 2 & 1.280 & 1.320 & 0.062 & 0.052 & 1.276 & 1.311 & 0.056 & 0.048 \\
\hline 2 & 0 & 2 & 2 & 1.204 & 1.232 & 0.064 & 0.038 & 1.198 & 1.225 & 0.058 & 0.033 \\
\hline 2 & 2 & 0 & 2 & 1.476 & 1.424 & 0.056 & 0.030 & 1.470 & 1.410 & 0.053 & 0.026 \\
\hline
\end{tabular}

Table 7. Comparison of experimental and predicted values.

\begin{tabular}{|c|c|c|c|c|c|c|c|c|c|c|c|c|}
\hline \multicolumn{4}{|c|}{ Front width (mm) } & \multicolumn{3}{|c|}{ Back width (mm) } & \multicolumn{3}{|c|}{ Front height (mm) } & \multicolumn{3}{|c|}{ Back height (mm) } \\
\hline $\begin{array}{l}\text { SI } \\
\text { No. }\end{array}$ & Experimental & Predicted & $\begin{array}{l}\text { Error } \\
(\%)\end{array}$ & Experimental & Predicted & $\begin{array}{c}\text { Error } \\
(\%)\end{array}$ & Experimental & Predicted & $\begin{array}{c}\text { Error } \\
(\%)\end{array}$ & Experimental & Predicted & $\begin{array}{l}\text { Error } \\
(\%)\end{array}$ \\
\hline 1 & 1.448 & 1.446 & 0.138 & 1.374 & 1.380 & -0.435 & 0.0609 & 0.0615 & -0.976 & 0.0498 & 0.0499 & -0.200 \\
\hline 2 & 1.592 & 1.593 & -0.063 & 1.522 & 1.519 & 0.197 & 0.0588 & 0.0592 & -0.676 & 0.0458 & 0.0466 & -1.717 \\
\hline 3 & 1.383 & 1.384 & -0.072 & 1.324 & 1.315 & 0.684 & 0.0630 & 0.0620 & 1.613 & 0.0490 & 0.0486 & 0.823 \\
\hline 4 & 1.504 & 1.503 & 0.067 & 1.442 & 1.447 & -0.346 & 0.0569 & 0.0580 & -1.897 & 0.0439 & 0.0448 & -2.009 \\
\hline 5 & 1.454 & 1.457 & -0.206 & 1.401 & 1.399 & 0.143 & 0.0581 & 0.0584 & -0.514 & 0.0453 & 0.0459 & -1.307 \\
\hline 6 & 1.487 & 1.482 & 0.337 & 1.418 & 1.418 & 0.000 & 0.0595 & 0.0584 & 1.884 & 0.0466 & 0.0453 & 2.870 \\
\hline 7 & 1.469 & 1.465 & 0.273 & 1.378 & 1.385 & -0.505 & 0.0599 & 0.0598 & 0.167 & 0.0468 & 0.0465 & 0.645 \\
\hline 8 & 1.462 & 1.463 & -0.068 & 1.402 & 1.396 & 0.430 & 0.0578 & 0.0580 & -0.345 & 0.0448 & 0.0453 & -1.104 \\
\hline 9 & 1.529 & 1.532 & -0.196 & 1.451 & 1.453 & -0.138 & 0.0599 & 0.0593 & 1.012 & 0.0470 & 0.0466 & 0.858 \\
\hline 10 & 1.591 & 1.596 & -0.313 & 1.508 & 1.510 & -0.132 & 0.0571 & 0.0573 & -0.349 & 0.0441 & 0.0440 & 0.227 \\
\hline 11 & 1.520 & 1.526 & -0.393 & 1.447 & 1.456 & -0.618 & 0.0572 & 0.0584 & -2.055 & 0.0441 & 0.0450 & -2.000 \\
\hline 12 & 1.562 & 1.562 & 0.000 & 1.506 & 1.505 & 0.066 & 0.0552 & 0.0546 & 1.099 & 0.0423 & 0.0418 & 1.196 \\
\hline 13 & 1.442 & 1.444 & -0.139 & 1.372 & 1.375 & -0.218 & 0.0605 & 0.0594 & 1.852 & 0.0474 & 0.0461 & 2.820 \\
\hline 14 & 1.384 & 1.387 & -0.216 & 1.306 & 1.312 & -0.457 & 0.0590 & 0.0596 & -1.007 & 0.0456 & 0.0461 & -1.085 \\
\hline 15 & 1.506 & 1.509 & -0.199 & 1.430 & 1.429 & 0.070 & 0.0600 & 0.0593 & 1.180 & 0.0470 & 0.0463 & 1.512 \\
\hline 16 & 1.420 & 1.423 & -0.211 & 1.356 & 1.358 & -0.147 & 0.0584 & 0.0578 & 1.038 & 0.0464 & 0.0458 & 1.310 \\
\hline 17 & 1.521 & 1.518 & 0.198 & 1.451 & 1.446 & 0.346 & 0.0598 & 0.0604 & -0.993 & 0.0468 & 0.0474 & -1.266 \\
\hline 18 & 1.580 & 1.579 & 0.063 & 1.514 & 1.514 & 0.000 & 0.0569 & 0.0566 & 0.530 & 0.0439 & 0.0436 & 0.688 \\
\hline 19 & 1.452 & 1.450 & 0.138 & 1.380 & 1.376 & 0.291 & 0.0575 & 0.0578 & -0.519 & 0.0445 & 0.0449 & -0.891 \\
\hline 20 & 1.427 & 1.425 & 0.140 & 1.358 & 1.357 & 0.074 & 0.0564 & 0.0565 & -0.177 & 0.0434 & 0.0433 & 0.231 \\
\hline 21 & 1.596 & 1.593 & 0.188 & 1.527 & 1.524 & 0.197 & 0.0582 & 0.0574 & 1.394 & 0.0453 & 0.0445 & 1.798 \\
\hline 22 & 1.466 & 1.465 & 0.068 & 1.397 & 1.395 & 0.143 & 0.0564 & 0.0575 & -1.913 & 0.0434 & 0.0445 & -2.472 \\
\hline 23 & 1.400 & 1.405 & -0.356 & 1.337 & 1.341 & -0.298 & 0.0636 & 0.0633 & 0.474 & 0.0516 & 0.0510 & 1.176 \\
\hline 24 & 1.461 & 1.451 & 0.689 & 1.384 & 1.375 & 0.655 & 0.0602 & 0.0609 & -1.149 & 0.0472 & 0.0481 & -1.871 \\
\hline 25 & 1.531 & 1.509 & 1.458 & 1.462 & 1.439 & 1.598 & 0.0606 & 0.0599 & 1.169 & 0.0476 & 0.0468 & 1.709 \\
\hline 26 & 1.581 & 1.509 & 4.771 & 1.512 & 1.439 & 5.073 & 0.0597 & 0.0599 & -0.334 & 0.0467 & 0.0468 & -0.214 \\
\hline 27 & 1.523 & 1.509 & 0.928 & 1.452 & 1.439 & 0.903 & 0.0607 & 0.0599 & 1.336 & 0.0477 & 0.0468 & 1.923 \\
\hline 28 & 1.519 & 1.509 & 0.663 & 1.450 & 1.439 & 0.764 & 0.0606 & 0.0599 & 1.169 & 0.0476 & 0.0468 & 1.709 \\
\hline 29 & 1.504 & 1.509 & -0.331 & 1.432 & 1.439 & -0.486 & 0.0607 & 0.0599 & 1.336 & 0.0477 & 0.0468 & 1.923 \\
\hline 30 & 1.501 & 1.509 & -0.530 & 1.433 & 1.439 & -0.417 & 0.0576 & 0.0599 & -3.840 & 0.0446 & 0.0468 & -4.701 \\
\hline 31 & 1.401 & 1.509 & -7.157 & 1.332 & 1.439 & -7.436 & 0.0597 & 0.0599 & -0.334 & 0.0456 & 0.0468 & -2.564 \\
\hline
\end{tabular}


Main Effccts Plot (data means) for front width (mm)

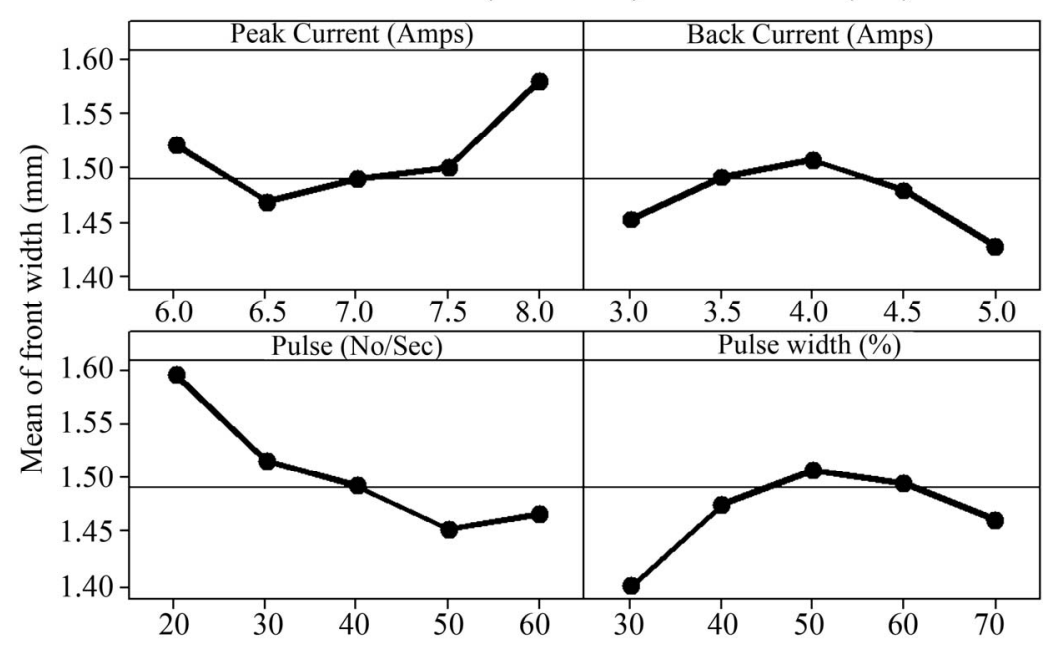

Figure 7. Main effects for front width.

Main Effccts Plot (data means) for back width (mm)

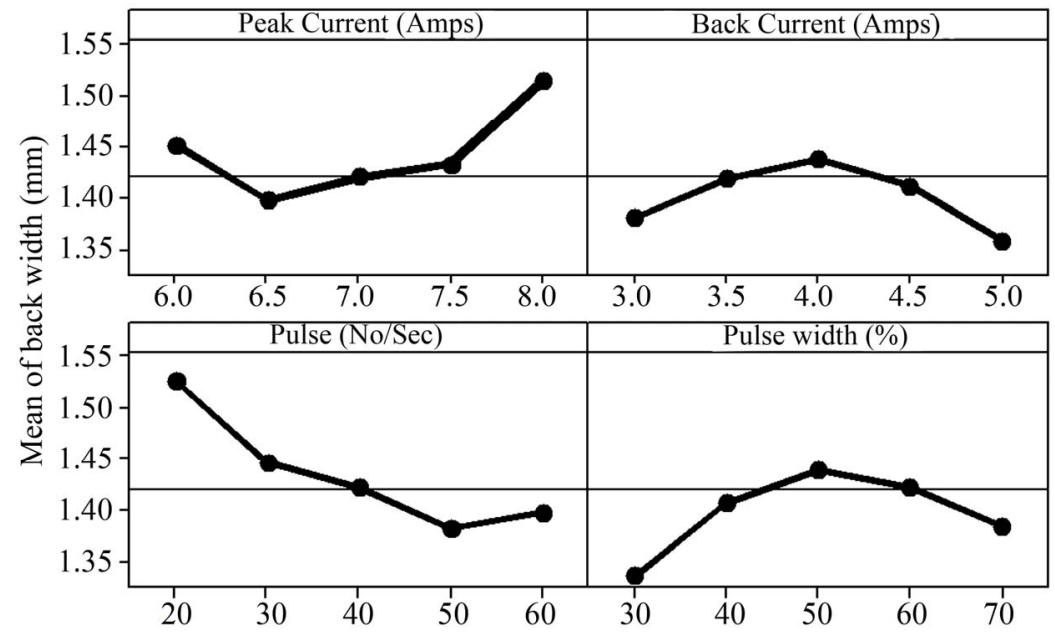

Figure 8. Main effects for back width.

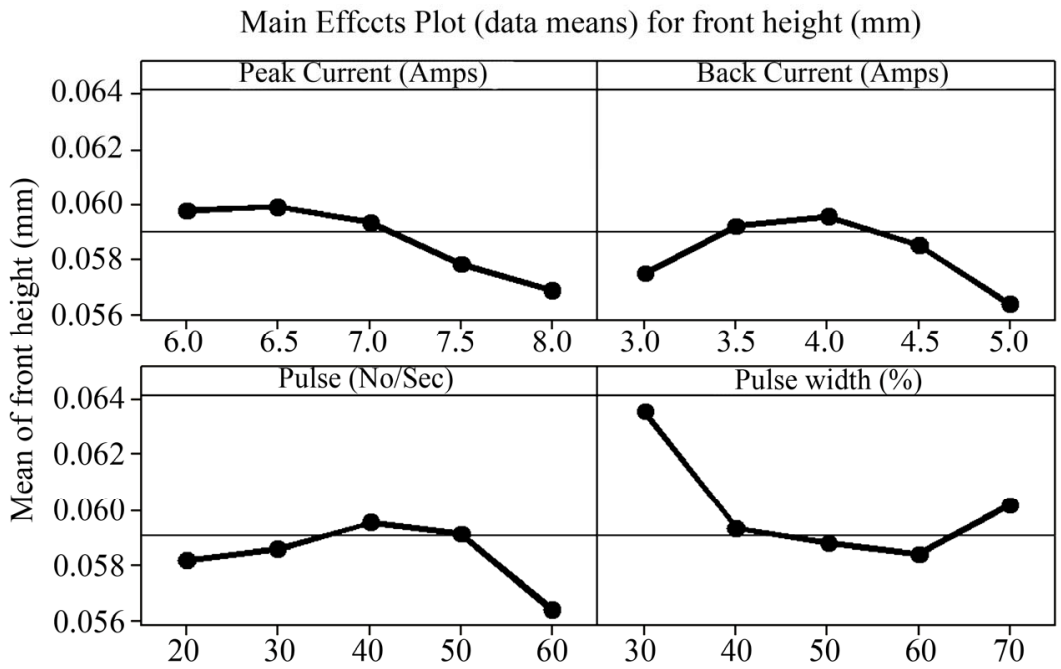

Figure 9. Main effects for front height. 


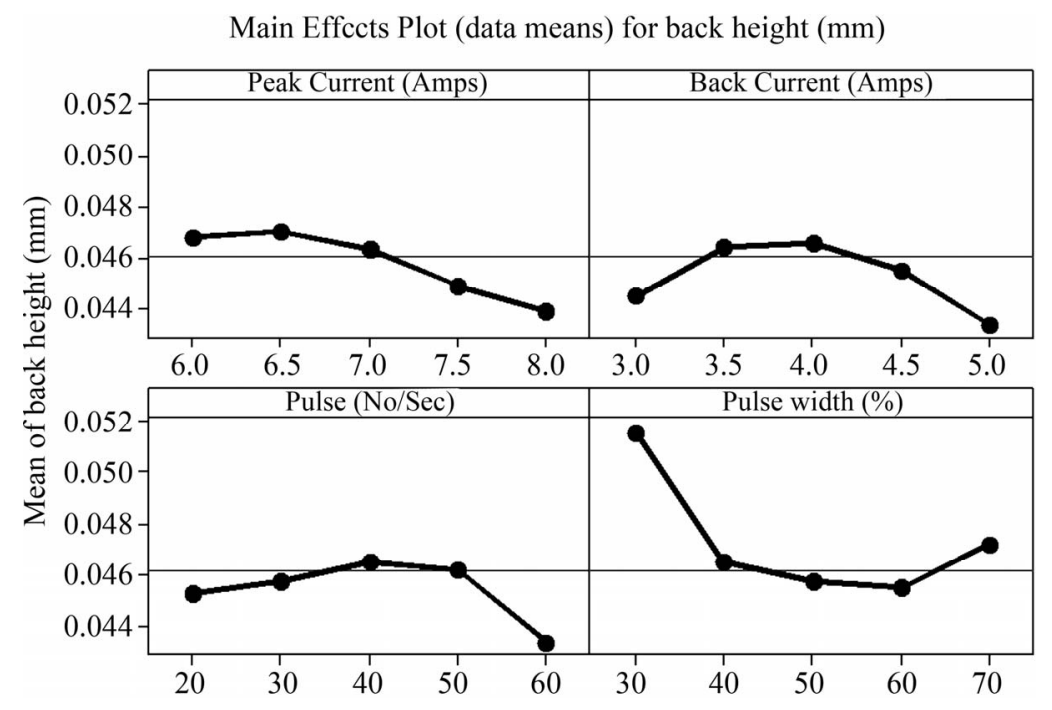

Figure 10. Main effects for back height.

\subsection{Effect of Back Current on Weld Pool Geometry Parameters}

Front width, back width, front height increases up to 4 Amperes and thereafter decreases, where as back height increases up to 3.5 Amperes and thereafter decreases. As the back current is helpful in maintaining continuous arc during welding, when the back current is low i.e. up to 4 Amperes, front width, back width and front height increases due to higher and dominating peak current which generates large amount of heat. When the back current is increased beyond 4 Amperes, it balances the heat input leading to lower heat input and hence front width, back width and front height decreases.

\subsection{Effect of Pulse Rate on Weld Pool Geometry Parameters}

Front width and back width decreases up to 50 pulses/ second and thereafter increases, where as front height increases up to 40 pulses/second and thereafter decreases and back height increases up to 30 pulses/second and thereafter decreases. This may be due to difference in heat input caused by variation of pulse rate. From 20 to 50 pulses/second, the interval between pulses is low and hence the heat input which enters the system at a moment decreases thereby decreasing the front width and back width. When the pulse rate increase beyond 50 pulses/sec heat input which enters the system at a moment increases thereby increasing the front width and back width.

\subsection{Effect of Pulse Width on Weld Pool Geometry Parameters}

Front width and back width increases up to 50\% and thereafter decreases, where as front height and back height decreases up to $60 \%$ and thereafter increases. The reason for effect of pulse width on weld pool geometry parameters is same as that of pulse rate. From $30 \%$ to $50 \%$ pulse width, the interval between pulse widths is high and hence the heat input which enters the system at a moment increases thereby increasing the front width and back width. When the pulse width increase beyond $50 \%$ heat input which enters the system at a moment decreases thereby decreasing the front width and back width.

From Figures 3-6, it was understood that a peak current of 6.5 Amperes, back current of 3.5 Amperes, pulse rate of 40 pulses/sec and pulse width of about $40 \%$ is found to produce optimum results.

\section{Conclusion}

A five level, four factor full, factorial design matrix based on the central composite rotatable design technique was used for the development of mathematical models to predict the weld pool geometry parameters for AISI $304 \mathrm{~L}$ stainless sheets welded by pulsed current micro plasma arc welding process. The prediction results using mathematical models are very close to the experimental results. Peak Current is the most dominating factor out of the selected parameters, since as peak current increases heat input increases leading to wider front and back widths and narrow front and back heights. For a peak current of 6.5 Amperes, back current of 3.5 Amperes, pulse rate of 40 pulses/second and pulse width of $40 \%$ the optimal weld pool geometry parameters can be achieved. The mathematical models are developed considering only four factors and five levels (peak current, back current, pulse rate and pulse width). However one may consider more number of factors and their levels to improve the mathematical model. 


\section{Acknowledgements}

The authors would like to thank Shri. R. Gopla Krishnan, Director, M/s Metallic Bellows (I) Pvt Ltd., Chennai for his support to carry out experimentation work.

\section{REFERENCES}

[1] T. D. Clark, "Department of Mechanical Engineering," Mater's Thesis, Brigham Young University, Provo, 2005.

[2] M. Balasubramanian, V. Jayabalan and V. Balasubramanian, "Effect of Process Parameters of Pulsed Current Tungsten Inert Gas Welding on Weld Pool Geometry of Titanium Welds," Acta Metallurgica Sinica (English Letters), Vol. 23, No. 4, 2010, pp. 312-320.

[3] M. Balasubramanian, V. Jayabalan and V. Balasubramanian, "Optimizing the Pulsed Current Gas Tungsten Arc Welding Parameters,” Journal of Materials Science \& Technology, Vol. 22, No. 6, 2006, pp. 821-825.

[4] G. M. Reddy, A. A. Gokhale and K. P. Rao, "Weld Microstructure Refinement in a 1441 Grade AluminiumLithium Alloy,” Journal of Materials Science, Vol. 32, No. 5, 1997, pp. 4117-4126. doi:10.1023/A:1018662126268

[5] D. K. Zhang and J. T. Niu, "Application of Artificial Neural Network Modeling to Plasma Arc Welding of Aluminum Alloys," Journal of Advanced Metallurgical Sciences, Vol. 13, No. 1, 2000, pp. 194-200.

[6] S.-C. Chi and L.-C. Hsu, “A Fuzzy Radial Basis Function Neural Network for Predicting Multiple Quality Characteristics of Plasma Arc Welding," Joint 9th IFSA World Congress and 20th NAFIPS International Conference, Vancouver, 25-28 July 2001, pp. 2807-2812.

[7] Y. F. Hsiao, Y. S. Tarng and W. J. Huang, “Optimization of Plasma Arc Welding Parameters by Using the Taguchi Method with the Grey Relational Analysis,” Journal of Materials and Manufacturing Processes, Vol. 23, No. 1, 2007, pp. 51-58. doi:10.1080/10426910701524527

[8] K. Siva, N. Muragan and R. Logesh, "Optimization of Weld Bead Geometry in Plasma Transferred Arc Hardfacing Austenitic Stainless Steel Plates Using Genetic Algorithm,” The International Journal of Advanced Manufacturing Technology, Vol. 41, No. 1-2, 2008, pp. 24-30. doi:10.1007/s00170-008-1451-3

[9] A. K. Lakshinarayana, V. Balasubramanian, R. Varaha- moorthy and S. Babu, "Predicted the Dilution of Plasma Transferred Arc Hardfacing of Stellite on Carbon Steel Using Response Surface Methodology," Metals and Materials International, Vol. 14, No. 6, 2008, pp. 779-789. doi:10.3365/met.mat.2008.12.779

[10] V. Balasubramanian, A. K. Lakshminarayanan, R. Varahamoorthy and S. Babu, "Application of Response Surface Methodolody to Prediction of Dilution in Plasma Transferred Arc Hardfacing of Stainless Steel on Carbon Steel,” International Journal of Iron and Steel Research, Vol. 16, No. 1, 2009, pp. 44-53.

[11] E. Taban, A. Dhooge and E. Kaluc, "Plasma Arc Welding of Modified 12\% Cr Stainless Steel," Materials and Manufacturing Processes, Vol. 24, No. 6, 2009, pp. 649-656. doi:10.1080/10426910902769152

[12] N. Kahraman, M. Taskin, B. Gulenc and A. Durgutlu, "An Investigation into the Effect of Welding Current on the Plasma Arc Welding of Pure Titanium," Kovove Mater, Vol. 48, No. 3, 2010, pp. 179-184.

[13] N. Srimath and N. Muragan, "Prediction and Optimization of Weld Bead Geometry of Plasma Transferred Arc Hardfacing Valve Seat Rings,” European Journal of Scientific Research, Vol. 51, No. 2, 2011, pp. 285-298.

[14] D. C. Montgomery, "Design and Analysis of Experiments," 3rd Edition, John Wiley \& Sons, New York, 1991.

[15] G. E. P. Box, W. H. Hunter and J. S. Hunter, "Statistics for Experiments,” John Wiley \& Sons, New York, 1978.

[16] J. Ravindra and R. S. Parmar, "Mathematical Model to Predict Weld Bead Geometry for Flux Cored Arc Welding,” Journal of Metal Construction, Vol. 19, 1987, pp. 45-52.

[17] W. G. Cochran and G. M. Cox, "Experimental Designs," John Wiley \& Sons Inc., London, 1957.

[18] T. B. Barker, “Quality by Experimental Design,” ASQC Quality Press, Milkwakee, 1985.

[19] W. P. Gardiner and G. Gettinby, "Experimental Design Techniques in Statistical Practice,” Horwood, Chichester, 1998.

[20] K. S. Prasad, Ch. S. Rao and D. N. Rao, "Prediction of Weld Pool Geometry in Pulsed Current Micro Plasma Arc Welding of SS304L Stainless Steel Sheets," International Transaction Journal of Engineering Management \& Applied Sciences \& Technologies, Vol. 2, No. 3, 2011, pp. 325-336. 